\title{
Macroeconomic Instability Index and Malaysia Economic Performance
}

\author{
Venus Khim-Sen Liew ${ }^{1}$, Racquel Anak Rowland ${ }^{1}$, Puah Chin Hong ${ }^{1}$, Jerome Kueh Swee Hui ${ }^{1}$, Rossazana Bt Ab \\ Rahim $^{1}$, Shirly Wong Siew Ling ${ }^{1}$ \\ Correspondence: Venus Khim-Sen Liew, Faculty of Economics and Business, Universiti Malaysia Sarawak, \\ 94300, Kota Samarahan, Sarawak, Malaysia.
}

Received: December 29, 2017

doi:10.5539/ibr.v11n3p179
Accepted: February 12, $2018 \quad$ Online Published: February 19, 2018

URL: https://doi.org/10.5539/ibr.v11n3p179

\begin{abstract}
The economic performance of Malaysia was affected by a series of financial crises that had induced macroeconomic instability in the country, which in turn had immensely dampened the nation's economic growth rate. No doubt Malaysia needs an indicator to monitor the nation's economic performance from time to time. This study attempts to construct such indicator known as Macroeconomic Instability Index (MII). The constructed MII shows two significant spikes at 1998 and 2008, which correspond to the Asian Financial Crisis and US Subprime Mortgage respectively, that had resulted in negative growth rate for GDP of Malaysia in 1999 and 2010. Results obtained from further analysis by the ARDL technique show that MII has negative and significance effects on economic performance. Moreover, MII has predictive power against economic performance as early as two periods in advance. The constructed MII could serve as end-product for policy purposes or intermediate-product for other economic and finance studies.
\end{abstract}

Keywords: macroeconomic instability index, Malaysia, economic performance

\section{Introduction}

The economic performance of Malaysia was affected by a series of financial crises that had induced macroeconomic instability in the country, which in turn had immensely dampened the nation's economic growth rate. For instance, the negative effect of 1997 Asian Financial Crisis and the 2007 US Subprime Mortgage Crisis (which turned into a fully-blown Global Financial Crisis in September 2008) caused Malaysian economy to perform poorly. These crises reduced Malaysia's exports as well as national aggregate demand. Many businesses failed and the non-performing loan of commercial banks escalated to 22.4\% in November 1998 from 6.5\% in 1997, just for an instance. In 1998, the output of the real economy declined plunging the country into its first recession for many years. During that year, the ringgit plunged below 4.7 and the KLSE fell below 270 points. Foreign direct investment inflow to Malaysia in 1998 also reduced by 59\% compared to 1997. As a result, the country's gross domestic product plunged $6.2 \%$ in 1998 . On the other hand, after the Global Financial Crisis, the contraction in manufacturing was steepest in export-oriented sectors that are facing the full brunt of the collapse in demand in developed markets. Overall, exports fell by $-7.5 \%$ in the fourth quarter of 2008 and $-20 \%$ in the first quarter of 2009. Electronics exports, which was badly affected, declined by $-44.0 \%$ in the first quarter and $-34.6 \%$ in the second quarter of 2009. Moreover, the construction sector contracted 23.5\%, manufacturing shrunk $9 \%$ and the agriculture sector 5.9\%. The unemployment rate rose from 3.2\% in 2007 to 3.7 \% in 2008 (Zainal Abidin and Rasiah, 2009). Stock market in Malaysia also fell from a closing index of 1445.03 in 2007 to 876.75 in 2008, amounting to fall of 39.3\%. Hence, it is obvious that Malaysia needs an indicator to monitor the nation's economic performance from time to time. In this conjunction, Macroeconomic Instability Index (MII) is an important indicator of a country's economic condition. This study aims to construct MII for Malaysia and analyses its impact on economic performance.

Macroeconomic instability was ambiguously defined back in those days, however, World Bank (1993) emphasized that budget deficit, foreign debt and the instability of exchange rates as influential factors in macroeconomics instability. In addition to this, World Bank (1993) made it clear that the foundation of macroeconomic stability in one's country is to have a constant growth rate, moderate or low inflation rate, and taking control of external debt and currency management. Since then, studies between macroeconomic instability and growth nexus became widely explored by economists and policymakers to formulate a perfect measurement for macroeconomic instability index (MII). 


\section{Literature Review}

Many economists argued chronic macroeconomic instability can put a damper to a sustainable growth. Previous literatures have put a lot of effort to estimate and explain macroeconomic instability proxies against economic growth. In the literature, there are several potential determinants of macroeconomic instability, for instance, inflation rate, budget deficit, trade deficit, unemployment, exchange rate, external debt and interest rate. The aforementioned factors create constraint to the economic growth. Nonetheless, early studies for instance Fosu (1992), Ghura and Grennes (1993), and Ramey and Ramey (1994) attempted to construct macroeconomic instability index using single variable. Using single index for macroeconomic instability, Fosu (1992) examines the role of export instability in the economic growth of African countries. The results showed that export instability had negative and significant effects on Non-African LDCs over the 1970-1986 period, but the negative effects are insignificant for African LDCs and Sub-Saharan African LDCs. Ghura and Grennes (1993) use a sample of 33 African countries over the period of 1972-1987 and show that real exchange rate (RER) misalignment constitutes to an adverse effect relationship with economic growth. On the other hand, Ramey and Ramey (1994) reveal that macroeconomic instability as constructed from inflation rate brings negative effect on the growth particularly for poor class of the economy. This study employs two samples of data which include 92 countries and 24 OECD countries for a period of 1960-1985 and 1950-1988 respectively.

Rather than using single variable to construct MII, Blance (1998) employs some macroeconomic instability proxies such as inflation, public deficit and a variety of public expenditure as a share of GDP and market distortion to be included in the equation as regressors. The study deduces that macroeconomic stability and market liberalization are prerequisite for economic growth. Ismihan, Metin-Ozcan and Tansel (2005) employ inflation rate, external debt to GNP, change in exchange rate and public deficit to GNP ratio that served as MII indicators. The result of the study affirms that macroeconomic instability become impediment to the capital formation as well as growth according to the experience of Turkey. In addition to this, a chronic macroeconomic instability in Turkey has a potential to destroy public investment particularly to its infrastructural component due to high record of budget deficit, high debt to GNP and high inflation rate. Sirimaneetham and Temple's (2009) construct MII using budget surplus, inflation, black market premium, currency overvaluation and exchange rate distortion to combine as an overall index and found that growth is strongly associated with macroeconomic stability in a sample of 70 developing economies from 1970-1999.

Another influential study by Haghighi, Sameti and Isfahani (2012) suggests that the level of macroeconomic instability index is highly related to the increase (decrease) of economic growth in the long run. The employment of inflation rate, real exchange rate, budget deficit and term-of-trade are combined and serve as macroeconomic instability index and estimated in the years from 1974-2008 in case of Iran. Similarly, Ahangari and Saki (2012) and Ahangari, Arman and Saki (2014) use macroeconomic instability index with inflation rate, budget deficit, external debt and free exchange rate to estimate the macroeconomic instability in Iran. More recently, Ali and Rehman (2015) also justify that the co-integration between macroeconomic instability and gross domestic product does exist in the case of Pakistan. It further elaborates that macroeconomic instability has deep rooted and bring detrimental impact on gross domestic product in Pakistan. The study incorporates inflation rate, unemployment rate, budget deficit and trade deficit as four sub-indices of macroeconomic instability index as regressors in the equation. The study focuses only on Pakistan which covers from 1980 till 2012. Autoregressive Distributed Lag (ARDL) used to measure the co-integration among the variables while Granger causality test estimates the causal relationship among the variables.

\section{Data and Methodology}

The study implements secondary time series data and are mainly retrieved from CEIC, Bank Negara Malaysia, International Monetary Fund and World Development Indicator by World Bank spanning from 1984-2016 to capture the relationship between macroeconomic instability and economic growth in Malaysia. In this section, the introduction of macroeconomic instability proxy is presented as macroeconomic instability index and the construction of such index followed the approach of Haghighi, Sameti and Isfahani (2012) and Ali and Rehman (2015). Before we proceeding to model estimation, formula of instability index for time series data of macroeconomic variables is illustrated as below:

$$
M I I_{t}=\sum_{j=1}^{n} W_{j}\left(\frac{Y_{j t}-\min Y_{j}}{\max Y_{j}-\min Y_{j}}\right)
$$


where $i=\{1,2, \ldots, n\} ; W_{j}$ represents a set of macroeconomic instability variables at time $t ; Y_{j t}$ represents actual value of “ $Y_{j}$ ” at time $t_{;} \min n Y_{j}$ and $\max Y_{j}$ represents the maximum and minimum value of series “ $Y_{j}$ " respectively throughout the period of study. The computed value of the composite index is limited to zero and one, with zero represents stability and one represents extreme instability (Ali and Rehman, 2015).

To estimate the impact of MII on economic performance, a set of conditioning variables, namely total labor force $(T L F)$, secondary school enrolment (SSE) and foreign direct investment (FDI) are included in the model and it is specified as follow:

$$
G D P P C_{t}=\alpha+\beta_{1} T L F_{t}+\beta_{2} S S E_{t}+\beta_{3} F D I_{t}+\beta_{4} M I I_{t}+\varepsilon_{t},
$$

where,

$G D P P C=$ gross domestic product per capita;

$T L F=$ total labor force,

$S S E$ = secondary school enrolment, and

$F D I=$ foreign direct investment.

Meanwhile, $\alpha$ is the constant term, $\beta_{1}$ to $\beta_{3}$ are the coefficients of conditioning variables and $\beta_{4}$ is the coefficient of macroeconomic instability index and $e_{t}$ is random error term. The effect of total labour force is expected to be positive because the increasing size of the workforce is giving an opportunity to gain economic expansion and accelerate gross domestic product in the statement of Amir, Khan and Bilal (2015). Besides, the impact of secondary school enrolment is expected to be positive because educated labor force can be productive and thus, bring benefit to the economy (Amir, Khan and Bilal, 2015). As for foreign direct investment, the coefficient is expected to be positive. Khor (2000) suggests that transfer of improved technology from developed countries to developing countries improve quality of factor of production and therefore, increases exports and savings which further stimulates investment and employment for higher economic performance. On the other hand, macroeconomic instability index is expected to have negative impact on the output since the increase in the index value means instability which can harm economic performance and vice-versa.

\section{Result and Data Analysis}

Here, MII is constructed for the case of Malaysia from the following variables: unemployment, inflation rate, budget deficit as percentage of per GDP, trade deficit and exchange rate depreciation rate. These variables are identified from the literature (Haghighi, Sameti and Isfahani; 2012; Ali and Rehman, 2015) as important components of MII. Equal weightage is attached to each variable. The constructed MII is plotted in Figure 1. It is evident from Figure 1 that over the $1984-2016$ period, MII reaches its height at 0.66 in the year 1998. The next highest value is 0.59 which is registered for 2008. Note that corresponding to these MII peaks are associated to the Asian Financial Crisis and US Subprime Mortgage Crisis respectively, which had resulted in negative growth rate for GDP of Malaysia in $1999(-7.40 \%)$ and $2010(-1.50 \%)$. Thus, it may be said that MII value that is approaching 0.60 is alarming. 


\section{MII}

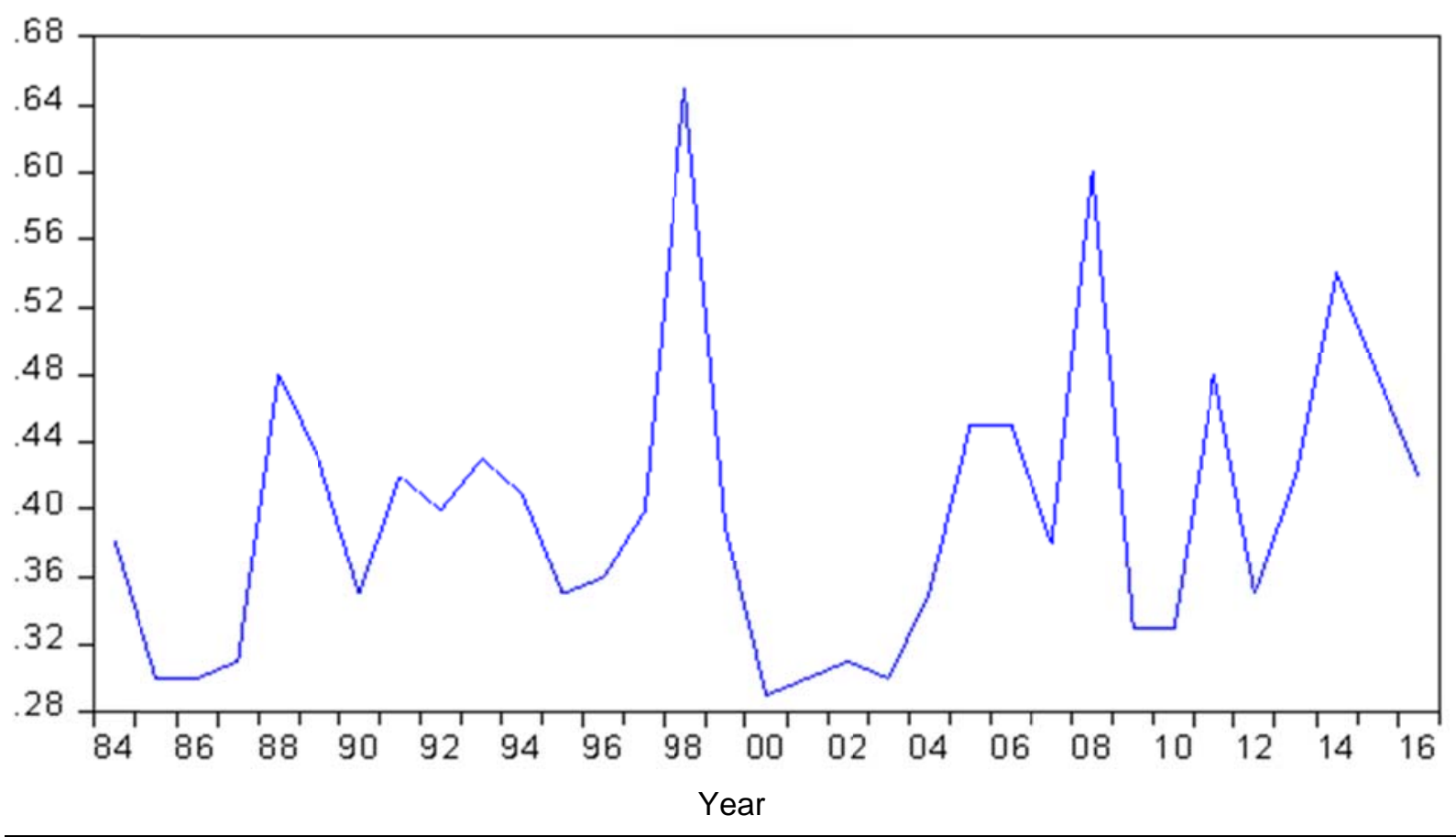

Figure 1. Macroeconomic Instability Index (MII) for Malaysia

Source: Authors' calculation.

Having constructed the MII, the next task is to examine its impact on economic performance as proxied by gross domestic product per capita. For this purpose, a set of control variables as depicted in Equation (2) are included in this study (Ali and Rehman, 2015). Table 1 provides a summary of the descriptive statistics of the dependent and independent variables as shown in Equation (2) for a sample of 1984-2016. Overall, the gross domestic product per capital (GDPPC), total labor force (TLF), secondary school enrolment (SSE) and foreign direct investment (FDI) are all normally distributed. This is known from the Jarque-Bera test results, which are all less than 0.05 in probability and therefore, the null hypothesis of normal distribution cannot be rejected.

Table 1. Descriptive Statistics

\begin{tabular}{lrrrrr}
\hline & GDPPC $^{\mathbf{a}}$ & TLF $^{\mathbf{b}}$ & SSE $^{\mathbf{b}}$ & FDI $^{\mathbf{a}}$ & MII \\
\hline Mean & 21840.02 & 9294.57 & 2056.59 & $4.90 \mathrm{E}+09$ & 0.45 \\
Median & 21997.83 & 9144.75 & 2176.86 & $4.00 \mathrm{E}+09$ & 0.45 \\
Maximum & 35035.04 & 14684.00 & 3037.93 & $1.51 \mathrm{E}+10$ & 0.66 \\
Minimum & 11485.53 & 5431.40 & 1141.39 & $1.15 \mathrm{E}+08$ & 0.15 \\
Std. Dev. & 7430.32 & 2676.24 & 590.48 & $3.96 \mathrm{E}+09$ & 0.14 \\
Jarque-Bera & 1.97 & 2.10 & 3.03 & 3.76 & 2.06 \\
Probability & 0.37 & 0.35 & 0.22 & 0.15 & 0.36 \\
\hline
\end{tabular}

Notes. ${ }^{\mathrm{a}}$ in US\$. ${ }^{\mathrm{b}}$ in thousand units. Jarque-Bera is a test statistic for testing whether the series is normally distributed.

Prior to the estimation of Equation (2), it is important to check the integration order of the variables. If all variables are integrated of order zero, which means they are stationary at their levels, then the equation can be estimated using the ordinary least squares (OLS) technique. Alternatively, if they are integrated of order 1 , when they achieve stationarity only after doing first differencing, then OLS could be applied if and only if they are cointegrated. However, if the variables are integrated of mixed orders of zero and one, then Autogressive Distributive Lag (ARDL) technique should be applied. To identify the integration order, this study adopts the Dickey-Fuller Test with Generalized Least Squares Detrending (DFGLS) of Elliot, Rothenberg, and Stock (1996). DFGLS stationarity test is essentially a modification of the commonly applied Augmented Dickey-Fuller (ADF) test in which the data are detrended beforehand. In this test, the null hypothesis of non-stationary series is contrasted with the alternative hypothesis of stationary series. The null hypothesis is rejected for test statistic that is smaller than the critical values obtained from MacKinnon simulations. Otherwise, the null hypothesis is maintained. The DFGLS results are presented in Table 2. 
Table 2 shows that GDPPC, SSE and TLF are not stationary in their levels, as the null hypothesis of stationary series could not be rejected at $5 \%$ significance level. However, their achieved stationarity after taking the first difference. Thus, it can be concluded that theses variables are integrated of order 1 . On the other hand, FDI and MII are determined to be stationary in their levels. So, they are considered as integrated of order zero. With these findings, since the variables are integrated with mixed orders of zero and one, ARDL technique rather than OLS technique is more appropriate to be adopted for the estimation of Equation (2). Thus, the ARDL technique which is available at EViews 9 is performed and the results obtained are reported in Table 3.

Table 2. Integration Order as Identified by DFGLS Stationarity Test

\begin{tabular}{llll}
\hline Variable & Level $^{\mathbf{a}}$ & First Difference $^{\mathbf{b}}$ & Integration Order $^{\text {(2.5 }}$ \\
\hline GDPPC & -2.58 & $-4.13^{* * *}$ & 1 \\
SSE & -2.16 & $-5.41^{* * *}$ & 1 \\
TIF & -1.63 & $-2.03^{*}$ & 1 \\
FDI & $-4.16^{* * *}$ & - & 0 \\
MII & $-5.02^{* * *}$ & - & 0 \\
\hline
\end{tabular}

Notes. ${ }^{\mathrm{a}}$ The test is estimated with Intercept and Trend. ${ }^{\mathrm{b}}$ The test is estimated with Intercept. ${ }^{* *}$ and ${ }^{* * *}$ indicate rejection of the null hypothesis at 5 and $1 \%$ significance levels respectively.

Table 3. Estimated ARDL Model

\section{General Information}

Dependent Variable: GDPPC

Included observations: 29 after adjustments

Maximum dependent lags: 4 (Automatic selection)

Model selection method: Akaike info criterion (AIC)

Dynamic regressors (4 lags, automatic): SSE TLF FDI MII

Number of models evaluated: 2500

Selected Model: ARDL(4, 4, 4, 4, 2)

HAC standard errors \& covariance (Bartlett kernel, Newey-West fixed bandwidth $=4.0000$ )

\begin{tabular}{|c|c|c|c|}
\hline 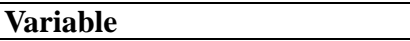 & Coefficient & $t$-Statistic & Probability \\
\hline $\mathrm{GDPPC}_{t-1}$ & 1.29 & 5.40 & 0.00 \\
\hline$G D P P C_{t-2}$ & -0.98 & -3.61 & 0.01 \\
\hline$G D P P C_{t-3}$ & 1.12 & 5.99 & 0.00 \\
\hline$G D P P C_{t-4}$ & -0.62 & -4.42 & 0.01 \\
\hline SSE & 0.00 & -2.08 & 0.08 \\
\hline$S S E_{t-1}$ & 0.01 & 5.24 & 0.00 \\
\hline$S S E_{t-2}$ & 0.00 & -1.10 & 0.31 \\
\hline$S S E_{t-3}$ & 0.00 & 2.36 & 0.06 \\
\hline$S S E_{t-4}$ & 0.00 & 1.47 & 0.19 \\
\hline$T L F$ & -1.74 & -3.97 & 0.01 \\
\hline$T L F_{t-1}$ & 1.91 & 4.22 & 0.01 \\
\hline$T L F_{t-2}$ & -0.07 & -0.11 & 0.92 \\
\hline$T L F_{t-3}$ & 3.25 & 3.94 & 0.01 \\
\hline$T L F_{t-4}$ & -5.98 & -7.72 & 0.00 \\
\hline FDI & 0.00 & 3.84 & 0.01 \\
\hline$F D I_{t-1}$ & 0.00 & 0.20 & 0.85 \\
\hline$F D I_{t-2}$ & 0.00 & 8.82 & 0.00 \\
\hline$F D I_{t-3}$ & 0.00 & -1.79 & 0.12 \\
\hline$F D I_{t-4}$ & 0.00 & 10.36 & 0.00 \\
\hline MII & -4490.55 & -5.03 & 0.00 \\
\hline$M_{t-1}$ & -6096.83 & -3.14 & 0.02 \\
\hline$M_{t-2}$ & -1335.41 & -2.23 & 0.07 \\
\hline Constant & 10638.60 & 10.81 & 0.00 \\
\hline Evaluation Criteria & & Statistic & Probability \\
\hline Adjusted $R^{2}$ & & 0.99 & \\
\hline F Test of Overall Significance & & 1265.09 & 0.00 \\
\hline Jarque-Bera & & 0.15 & 0.93 \\
\hline Breusch-Godfrey LM Test & & 4.22 & 0.10 \\
\hline Breusch-Pagan-Godfrey & & 2.65 & 0.11 \\
\hline
\end{tabular}

As seen in Table 3, the optimal lags for GDPPC, SSE, TLF, FDI and MII are 4,4,4,4 and 2 respectively. These lags are selected based on Akaike information criterion. The selected model has passed through a battery of diagnostic tests on the model's residuals. Specifically, the residuals are normally distributed by the Jarque-Bera test, since the probability of the test statistic is 0.00 , which is less than conventional significance level, for 
instance 0.10. Besides, the Breusch-Godfrey LM Serial Correlation Test result indicates no serial correlation in residuals. Meanwhile, the Breusch-Pagan-Godfrey heteroscedasticity Test result shows no heteroscedasticity in the residuals. The F-statistics reveals the overall significance of the included independent variables and the R2 value indicates that these variables can explained $99 \%$ of the variations in the dependent variables, i.e., GDPPC. Thus, this model has fitted the data excellence well and it is thus suitable for interpretation.

The results as shown in the middle panel of Table 3 indicate that GDPPC is significantly affected by the present and past values of itself and all the control variables. Moreover, the variable of interest in this study, i.e., MII has negative effects on GDPPC and the effects are significance at $10 \%$ level. In this respect, GDPPC is also significantly affected by the present $\left(\mathrm{MII}_{\mathrm{t}}\right)$ and the two past values $\left(\mathrm{MII}_{\mathrm{t}-1}, \mathrm{MII}_{\mathrm{t}-2}\right)$. This means $\mathrm{MII}$ has predictive power against GDPPC as early as two periods ahead. In addition, as the current value of GDPPC is significantly affected by the two lagged values of MII, this is essentially meaning that GDPPC is Granger caused by MII.

\section{Conclusion}

The economic performance of Malaysia was affected by a series of financial crises that had induced macroeconomic instability in the country, which in turn immensely dampened the nation's economic growth rate. For instance, the negative effect of 1997 Financial Crisis and the 2008 US Subprime Mortgage Crisis caused Malaysian economy to perform poorly. Typically, Malaysia gross domestic product experienced an economy contraction of $7.4 \%$ in 1998 . Malaysian production growth was exposed to high inflation, excessive budget deficit and negative trade balance when the economy slumped into recession in 1997. Hence, it is obvious that Malaysia needs an indicator to monitor the nation's economic performance from time to time. In this conjunction, Macroeconomic Instability Index (MII) is an important indicator of a country's economic condition.

This study is taken up to construct the MII for the case of Malaysia. The variables adopted to construct this index include unemployment, inflation rate, budget deficit as percentage of per GDP, trade deficit and exchange rate depreciation rate. The constructed MII shows two spikes at 1998 (MII=0.66) and 2008 (MII=0.59), which correspond to the Asian Financial Crisis and US Subprime Mortgage Crisis respectively, that had resulted in negative growth rate for GDP of Malaysia in 1999 and 2010. Results obtained from further analysis by the ARDL technique show that MII has negative and significance effects on economic performance. Moreover, it is found that MII has predictive power against economic performance as early as two periods ahead.

The constructed MII could serve as end-product for policy purposes or intermediate-product for other economic and finance studies. The potential users of this new index include governments, exporters, foreign direct investors, international firms, corporations, bankers, fund managers, stock market and foreign exchange markets participants.

\section{Acknowledgement}

The authors acknowledge UNIMAS for its special research grant, F01/SpFRC/1435/1613.

\section{References}

Ahangari, A., \& Saki, A. (2012). A study on the effect of macroeconomic instability index on private investment in Iran. Management Science Letters, 2, 1939-1946. https://doi.org/10.5267/j.msl.2012.06.028

Ahangari, A., Arman, A., \& Saki, A. (2014). The estimation of Iran's macroeconomics instability index. Management Science Letters, 4, 871-882. https://doi.org/10.5267/j.msl.2014.4.003

Ali, A., \& Rehman, H. U. (2015). Macroeconomic instability and its impact on gross domestic product: An empirical analysis of Pakistan. Pakistan Economic and Social Review, 53(2), 285-316.

Amir, H., Khan, M., \& Bilal, K. (2015). Impact of educated labor force on economic growth of Pakistan: A human capital perspective. Journal of Natural and Social Sciences, 4(4), 814-831.

Blance, S. R. (1998). Macroeconomic stability and economic growth: the case of Spain. Applied Economics Letters, 5(9), 587-591. https://doi.org/10.1080/758529505

Elliot, G., Rothenberg, T. J., \& Stock, J. H. (1996). Efficient Tests for an Autoregressive Unit Root, Econometrica, 64, 813-836. https://doi.org/10.2307/2171846

Fosu, A. K. (1992). Effect of export instability on economic growth in Africa. The Journal of Developing Areas, 26(3), 323-332.

Ghura, D., \& Grennes, T.J. (1993). The real exchange rate and macroeconomic performance in Sub-Saharan Africa. Journal of Development Economics, 42, 155-174. https://doi.org/10.1016/0304-3878(93)90077-Z

Haghighi, H. K., Sameti, M., \& Isfahani, R. D. (2012). The effect of macroeconomic instability on economic 
growth. Research in Applied Economics, 4(3), 39-61.

Ismihan, M., Metin-Ozcan, K., \& Tansel, A. (2005). The role of macroeconomic instability in public and private capital accumulation and growth: The case of Turkey 1963-1999. Applied Economics, 37, 239-251. https://doi.org/10.1080/0003684042000286115

Khor, M. (2000). Globalization and the South: Some critical issues, 47. Malaysia: Third World Network.

Ramey, G., \& Ramey, V. A. (1995). Cross-country evidence on the link between volatility and growth. The American Economic Review, 85(5), 1138-1151.

Shazali, M., Puah, C. H., Liew, V. K. S., \& Wong, S. S. L. (2015). An early warning indicator of economic vulnerability constructing for Malaysian economy. Economic Annals-XXI, 3(1), 37-41.

Sirimaneetham, V., \& Temple, J. R. W. (2009). Macroeconomic stability and the distribution of growth rate. The World Bank Economic Review, 23(3), 443-479. https://doi.org/10.1093/wber/lhp008

Wong. S. S. L., Puah, C. H., Shazali, M., \& Liew, V. K. S. (2016). Measuring Business Cycle Fluctuations: An Alternative Precursor to Economic Crises. Economic Computation and Economic Cybernetics Studies and Research, 50(4), 235-248.

World Bank. (1993). The East Asian economic miracle: Economic growth and public policy.

Zainal, A. M., \& Rasiah, R. (2009). The Global Financial Crisis and the Malaysian Economy: Impact and Responses.A joint Report by Institute of Strategic and International Studies, Universiti Malaya and United Nations Development Programme. Available at: http://www.isis.org.my/attachments/e-books/The_Global_Financial_Crisis_and_the_Malaysian_Economy.p df

\section{Copyrights}

Copyright for this article is retained by the author(s), with first publication rights granted to the journal.

This is an open-access article distributed under the terms and conditions of the Creative Commons Attribution license (http://creativecommons.org/licenses/by/4.0/). 